Article

\title{
Electrochemical Disinfection of Dental Implants Experimentally Contaminated with Microorganisms as a Model for Periimplantitis
}

\author{
Maximilian Koch ${ }^{1}\left(\mathbb{D}\right.$, Maximilian Göltz ${ }^{2}$, Meng Xiangjun ${ }^{1}$, Matthias Karl ${ }^{3, * \mathbb{D}}$, \\ Stefan Rosiwal ${ }^{4}$ (D) and Andreas Burkovski ${ }^{1}$ (D) \\ 1 Microbiology Division, Department of Biology, University of Erlangen-Nuremberg, 91058 Erlangen, \\ Germany; Maximilian.G.F.Koch@gmx.de (M.K.); mengxiangjun1992@gmail.com (M.X.); \\ Andreas.burkovski@fau.de (A.B.) \\ 2 Division of ultra-hard coatings, Department of Material Sciences, University of Erlangen-Nuremberg, \\ 91058 Erlangen, Germany; maximilian.goeltz@fau.de \\ 3 Department of Prosthodontics, Saarland University, 66421 Homburg/Saar, Germany \\ 4 Chair of Materials Science and Engineering for Metals, Department of Material Sciences, University of \\ Erlangen-Nuremberg, 91058 Erlangen, Germany; Stefan.Rosiwal@fau.de \\ * Correspondence: matthias.karl@uks.eu; Tel.: +49-6841-1624900
}

Received: 17 January 2020; Accepted: 6 February 2020; Published: 9 February 2020

\begin{abstract}
Despite several methods having been described for disinfecting implants affected by periimplantitis, none of these are universally effective and may even alter surfaces and mechanical properties of implants. Boron-doped diamond (BDD) electrodes were fabricated from niobium wires and assembled as a single instrument for implant cleaning. Chemo-mechanical debridement and air abrasion were used as control methods. Different mono-species biofilms, formed by bacteria and yeasts, were allowed to develop in rich medium at $37^{\circ} \mathrm{C}$ for three days. In addition, natural multi-species biofilms were treated. Implants were placed in silicone, polyurethane foam and bovine ribs for simulating different clinical conditions. Following treatment, the implants were rolled on blood agar plates, which were subsequently incubated at $37^{\circ} \mathrm{C}$ and microbial growth was analyzed. Complete electrochemical disinfection of implant surfaces was achieved with a maximum treatment time of 20 min for Candida albicans, Candida dubliniensis, Enterococcus faecalis, Roseomonas mucosa, Staphylococcus epidermidis and Streptococcus sanguinis, while in case of spore-forming Bacillus pumilus and Bacillus subtilis, a number of colonies appeared after BDD electrode treatment indicating an incomplete disinfection. Independent of the species tested, complete disinfection was never achieved when conventional techniques were used. During treatment with BDD electrodes, only minor changes in temperature and $\mathrm{pH}$ value were observed. The instrument used here requires optimization so that higher charge quantities can be applied in shorter treatment times.
\end{abstract}

Keywords: air abrasion; antimicrobial treatment; biofilm; boron-doped diamond; mechanical debridement; reactive oxygen species

\section{Introduction}

While a consistent definition of periimplantitis [1] as well as diagnostic criteria defining this disease are still missing [2,3], periimplantitis has received tremendous attention during the past years [3]. In addition, considerable heterogeneity exists among reports on the prevalence of periimplantitis [3]. A systematic review and meta-analysis conducted by Dreyer and coworkers found prevalence on implant level between $1.1 \%$ and $85.0 \%$ [2], while Rakic and coworkers found prevalence of $12.8 \%$ at 
implant level [4]. Irrespective of the exact numbers, periimplantitis remains being a complication, threatening long-term implant survival $[5,6]$.

According to a recent literature review, periimplantitis has a multifactorial etiology [3] for which several risk factors $[7,8]$ have been described. These include patient-specific factors such as genetic disorders, smoking [1] and periodontal disease $[9,10]$, cement or impression material remnants in the periimplant sulcus [11,12], bacterial contamination of the implant components [13], technical issues and implant surface characteristics $[5,10,14]$.

Several attempts already have been made aimed at characterizing periimplant lesions as well as differences between teeth and implants with respect to pathologic processes [15,16]. While the exact patho-mechanisms seem not to be fully understood, it appears to be consensus that bacterial biofilms on dental implants $[13,17]$ can cause an inflammatory reaction $[12,18,19]$, resulting in loss of periimplant bone [20,21]. However, it has also been pointed out that marginal bone loss around dental implants may result from the bone's response to surgical trauma and implant loading which must be differentiated from periimplantitis [22].

Most treatment strategies depend on the clinical situation considering probing depth, suppuration, periodontal indices such as bleeding on probing and plaque index as well as radiographic bone loss [3,23-25] as decisive factors. Treatment may then range from implant debridement, resective and reconstructive surgery [23] to implant removal [26]. According to several authors, treatment of periimplantitis is considered as having an unpredictable outcome $[6,20]$ in particular when evaluating the effectiveness of regenerative treatment $[23,27]$.

A broad variety of techniques for the disinfection of dental implants has been described in the literature [26]. These include mechanical instrumentation [28,29], chemical and antimicrobial agents [30], treatment with local or systemic antibiotics [17,29,31], laser application [32], photodynamic therapy [18,33,34], cold plasma treatment [35,36] and air abrasion [37-40]. In many instances, only combinations of different disinfection techniques have been shown to be effective [36,40-42], with mechanical debridement bearing the risk of implant surface alterations [43]. A novel and just recently published approach employs electrochemical principles for in situ removal of biofilm from textured dental implant surfaces using the implant itself as an electrode [44].

In this preliminary proof of principle study, we tested the application of boron-doped diamond (BDD) electrodes [45-47] for the electrochemical disinfection of dental implants colonized by biofilm-forming microorganisms. The working principle of these electrodes is based on the electrolytic dissociation of water, which theoretically produces hydrogen at the negative pole (cathode) and oxygen at the positive pole (anode). Due to the properties of the electrode material used, a higher voltage than theoretically needed is required (overpotential). When diamond electrodes are being used, an overpotential of $2.8 \mathrm{~V}$ is required for anodic oxygen production while the desired disinfective $\mathrm{OH}$ radicals are generated already at $2.5 \mathrm{~V}$.

\section{Materials and Methods}

\subsection{Preparation of Electrodes}

Diamond coating with boron doping of thin niobium wires $(200 \mu \mathrm{m}$ in diameter $)$ was performed in a Hot-Filament Chemical Vapor Deposition machine at approx. $800{ }^{\circ} \mathrm{C}$ in a methane-hydrogen-trimethylborate gas atmosphere at 2 mbar for $6 \mathrm{~h}$. The functionality and the manageability of the diamond coatings where verified using bending tests. Optimal properties with respect to stiffness and surface roughness were obtained when the niobium wires were sandblasted (air pressure 4 bar) with silicon-carbide particles approximately $46 \mu \mathrm{m}$ in size prior to BDD coating. A special wire coating setup was developed to minimize deformation of the wires during diamond coating. With this approach, a reproducible thickness of the dense diamond coating of approximately $2 \mu \mathrm{m}$ could be achieved (Figure 1). Two of these electrodes were combined with electrical insulating 
media to form a probe-like instrument with clinically applicable dimensions (Figure 2). This probe was connected to an external electric power supply allowing for adjusting voltage and treatment time.

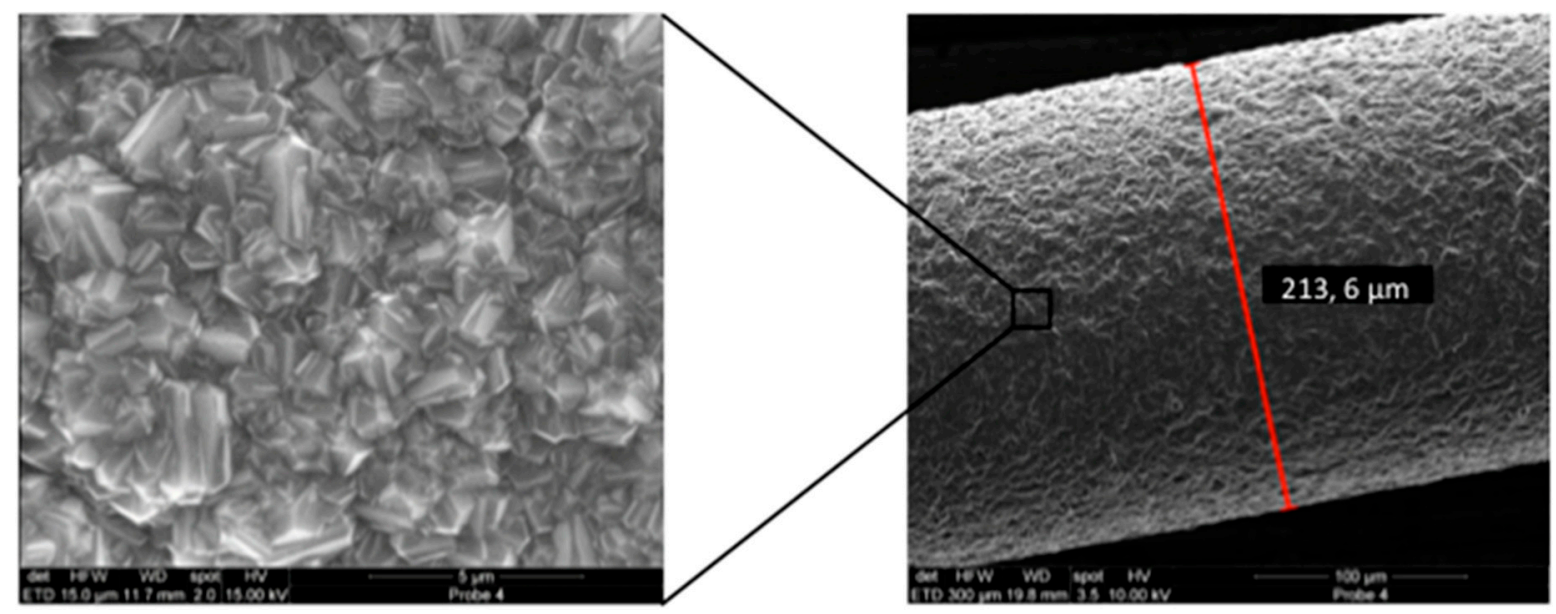

Figure 1. Scanning electron microscopy (SEM) image of a niobium wire after boron doped diamond (BDD) coating (Right: Overview; Left: Close up view of the area indicated by black rectangle). The coating layer has an approximate thickness of $2 \mu \mathrm{m}$ and shows no delamination.

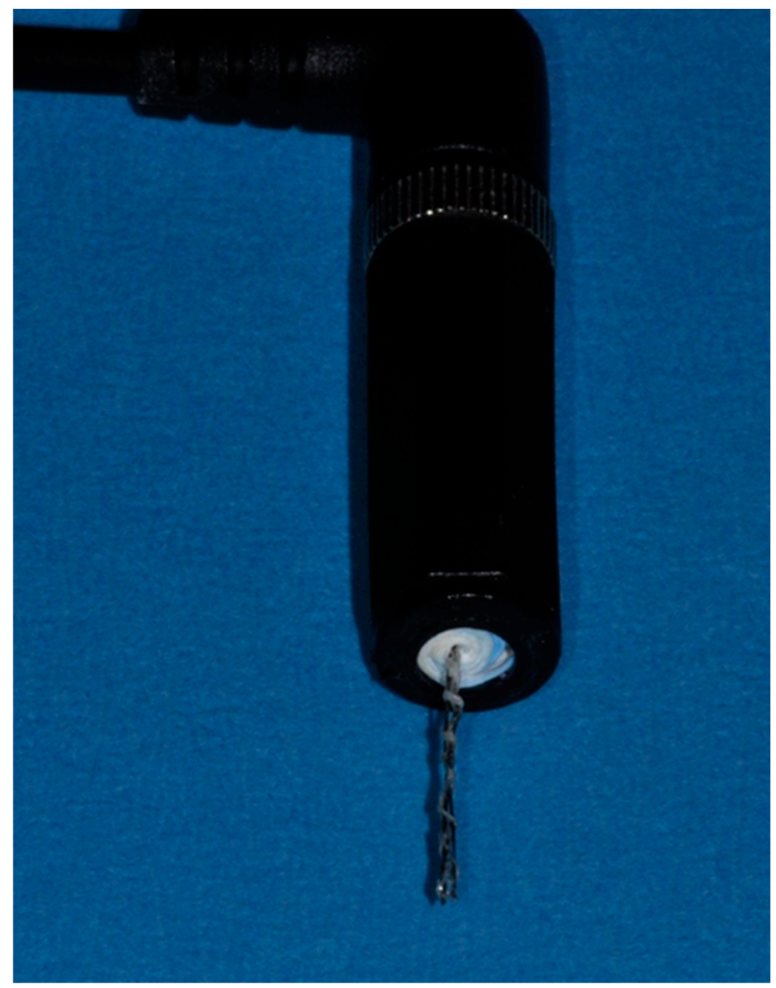

Figure 2. Disinfection apparatus consisting of an electrode array with intermediate insulating material.

\subsection{Treatment of Experimentally Contaminated Implants as Periimplantitis Model}

Forty-five commercially available dental implants with a medium rough surface (Straumann Bone Level Tapered 4.1 x 12 mm RC; REF: 021.5512; LOT: RP027) were exposed to different microbes for three days at $37{ }^{\circ} \mathrm{C}$ in rich medium [Brain Heart Infusion (BHI); Oxoid, Wesel, Germany] to allow biofilm formation on external and internal surfaces (Note: Implants were reused following sterilization in an autoclave in order to increase sample size; please cf. Table S1). The microorganisms applied included yeasts (Candida albicans, Candida dubliniensis), Gram-negative (Roseomonas mucosa) 
and Gram-positive bacteria (Enterococcus faecalis, Staphylococcus epidermidis, Streptococcus sanguinis), including spore-forming bacteria (Bacillus pumilus, Bacillus subtilis) (Table 1). The microorganisms were chosen based on their robustness and occurrence in cases of infected root canals [31,32] as well as in cases of peri-implantitis [33,34]. Often found members of the genera Prevotella and Treponema were not included in the study, since these anaerobic and microaerophilic bacteria are highly oxygen-sensitive and less resistant against reactive oxygen species and even atmospheric oxygen concentrations. For control of biofilm formation, staining and quantitative analysis was carried out as described previously [48].

Table 1. Microorganisms used in this study.

\begin{tabular}{|c|c|c|}
\hline Species & Description & Reference/Source \\
\hline \multicolumn{3}{|c|}{ Bacteria } \\
\hline Bacillus pumilus & $\begin{array}{l}\text { Gram-positive isolate from infected root canal, } \\
\text { spore former }\end{array}$ & [49] \\
\hline Bacillus subtilis & Strain 168, Gram-positive spore former & $\begin{array}{l}\text { Bacillus Genetic Stock Centre } \\
\text { (Columbus, OH, USA) }\end{array}$ \\
\hline Enterococcus faecalis & DSM 20478, type strain, Gram-positive & $\begin{array}{l}\text { German Type Culture Collection, } \\
\text { DSMZ, Braunschweig, Germany }\end{array}$ \\
\hline Roseomonas mucosa & Gram-negative isolate from infected root canal & [50] \\
\hline Staphylococcus epidermidis & DSM 20044, type strain, Gram-positive & $\begin{array}{l}\text { German Type Culture Collection, } \\
\text { DSMZ, Braunschweig, Germany }\end{array}$ \\
\hline Streptococcus sanguinis & DSM 20567, type strain, Gram-positive & $\begin{array}{l}\text { German Type Culture Collection, } \\
\text { DSMZ, Braunschweig, Germany }\end{array}$ \\
\hline \multicolumn{3}{|c|}{ Yeasts } \\
\hline Candida albicans & Strain SC5314 & Laboratory stock \\
\hline Candida dubliniensis & Isolate from infected root canal & [50] \\
\hline
\end{tabular}

The implants were either placed in (i) elastic silicone, stable against temperature, acid, base and oxidants and bacterial colonization (Bindulin, Fürth, Germany), mimicking periimplant soft tissue, polyurethane foam blocks (Cellular Rigid polyurethane foam 20pcf, Sawbones Europe AB, Malmö, Sweden) mimicking type IV alveolar bone (Figure 3) according to the Lekholm and Zarb classification [51] or in bovine ribs. In the latter cases, osteotomies were created in preformed saucer-shaped defects applying the regular surgical protocol [39]. The defects simulated circular bone resorption under maintenance of the buccal and oral compacta resembling class Ie defects according to a clinical classification system [52]. These specimens were placed in containers filled with phosphate-buffered saline ( $137 \mathrm{mM} \mathrm{NaCl}, 2.7 \mathrm{mM} \mathrm{KCl}, 10 \mathrm{mM} \mathrm{Na}_{2} \mathrm{HPO}_{4}, 2 \mathrm{mM} \mathrm{KH}_{2} \mathrm{PO}_{4}, \mathrm{pH} 7.4$ ) and treated applying the following methods: (i) Mechanical debridement (stainless steel curettes (EXD11/12, HuFriedy, Chicago, IL, USA), polishing of accessible implant surfaces) and irrigation with chlorhexidine (Chlorhexamed FORTE ethanol-free 0.2\%, GlaxoSmithKline Consumer Healthcare GmbH \& Co. KG, Munich, Germany) for a total of 5 min. (ii) Air abrasion (AIRFLOW PLUS, EMS ElectroMedicalSystems $\mathrm{GmbH}$, Munich, Germany) and irrigation with chlorhexidine (Chlorhexamed FORTE ethanol-free $0.2 \%$, GlaxoSmithKline Consumer Healthcare GmbH \& Co. KG) for a total of $5 \mathrm{~min}$. (iii) Electrochemical disinfection using the electrode configuration described above applying different treatment times. For every species investigated, at least 3 biological replicates were tested for each treatment procedure.

After cleaning and disinfection, the implants were rolled five to seven times on Columbia Blood Agar plates (Oxoid, Wesel, Germany), which were subsequently incubated at $37^{\circ} \mathrm{C}$ for one day. Bacterial growth was monitored and rated using an evaluation scheme adapted from a monitoring scheme of catheter infections [53]. To this end, each lane of the roll-out was rated from 0 (no growth) to 3 (strong growth) using a master sample as reference (Figure 4). All experiments were carried out in independent replicates ( $n=3$ biological replicates). 


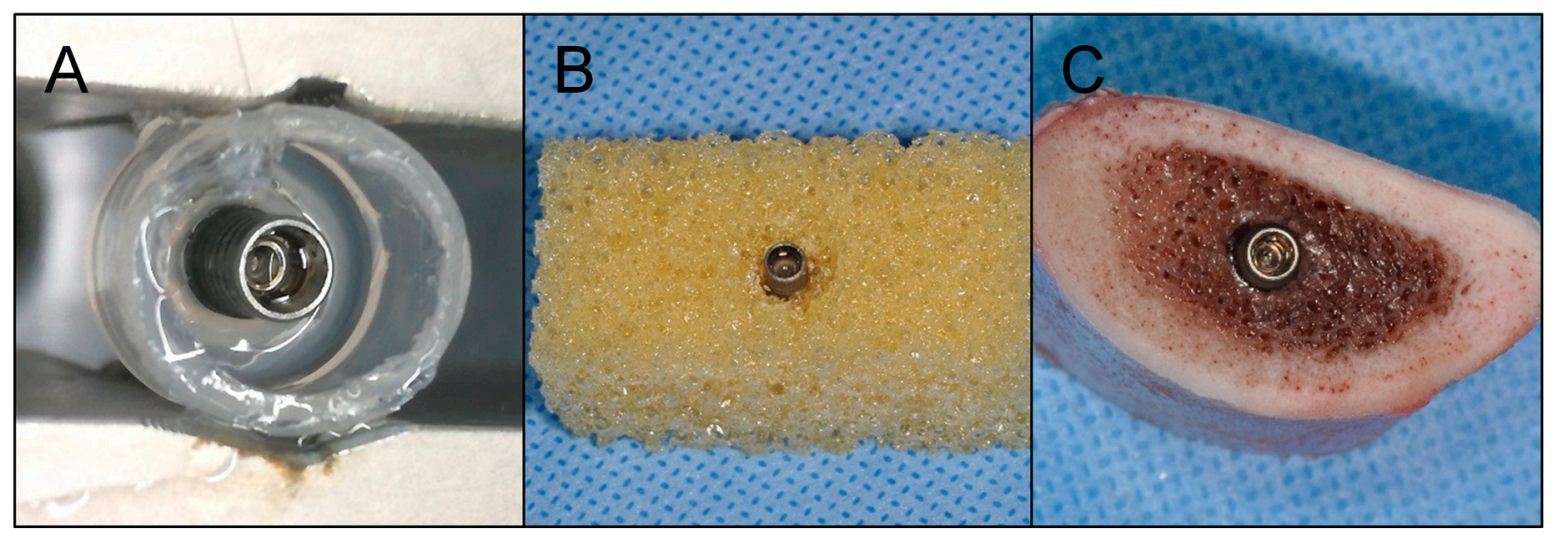

Figure 3. Placement of dental implants in model substrates. (A) Silicone simulating periimplant soft tissue, (B) polyurethane foam mimicking type IV alveolar bone with a circumferential defect and (C) bovine ribs.

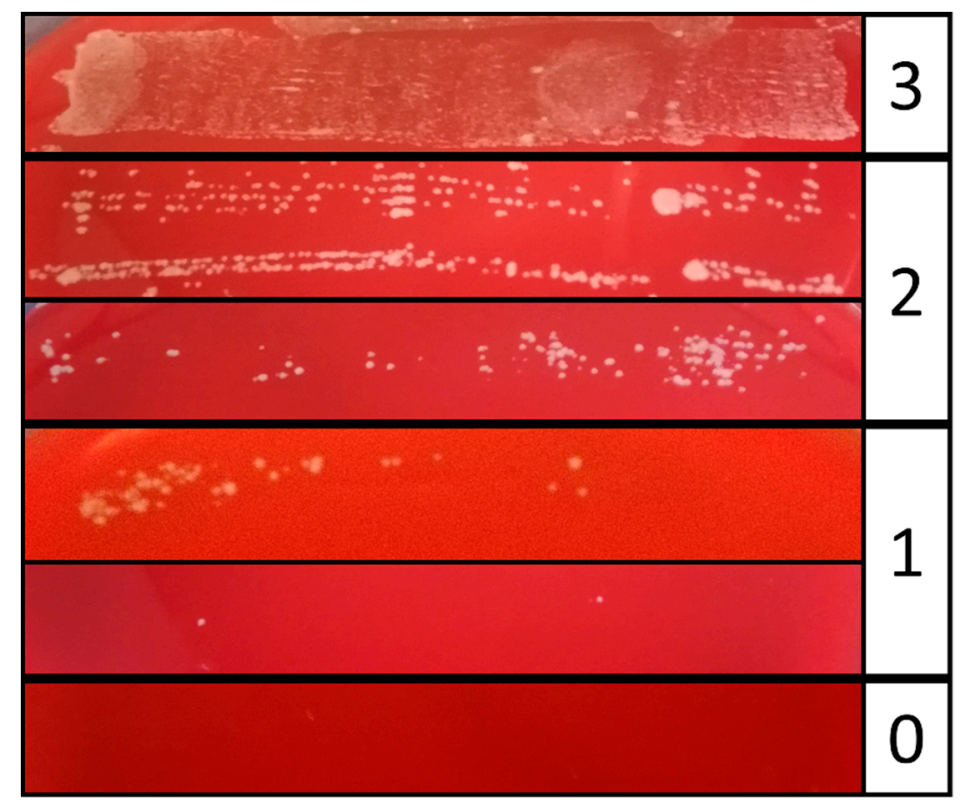

Figure 4. Evaluation scheme for microbial growth. Treated implants were rolled on Columbia Blood Agar plates and incubated at $37^{\circ} \mathrm{C}$. Growth of the individual roll-outs was scored from $0=$ no bacterial growth, 1 = minor growth, 2 = major growth, 3 = strong growth.

\subsection{Statistical Analysis}

The ratings obtained for mechanical debridement, air abrasion and 5 min BDD electrode treatment of implants $(n=3)$ covered by E. faecalis, $C$. dubliniensis and multi-species biofilm were subject to comparative statistical analysis. To this end, the sums of the individual ratings were used. In view of the small sample sizes, the integer valued results cannot be assumed to be normally distributed. Therefore, the parameter-free Kruskal Wallis rank sum test $(R$, version 3.6.2, The R Foundation for Statistical Computing, Vienna, Austria; www.R-project.org) was applied to compare the different treatments. The level of significance was set at $\alpha=0.05$. 


\section{Results}

\subsection{Biofilm Formation on Experimetally Contaminated Implants}

It was the aim of this study, to investigate the elimination of biofilms on implants using BDD electrodes as new electrochemical treatment method for periimplantitis. As a prerequisite of our experiments, implants were incubated in rich medium with distinct microbial species for several days. Subsequently, biofilm formation was tested by staining with crystal violet solution. In all cases, biofilm formation on implants was observed; however, in a species-specific amount. The strongest mono-species biofilm producers were B. subtilis and C. dubliniensis, moderate amounts of biofilm were produced by B. pumilus, R. mucosa and S. sanguinis, while the poorest colonization of implants tested here was observed for C. albicans, E. faecalis and S. epidermidis (Figure 5).

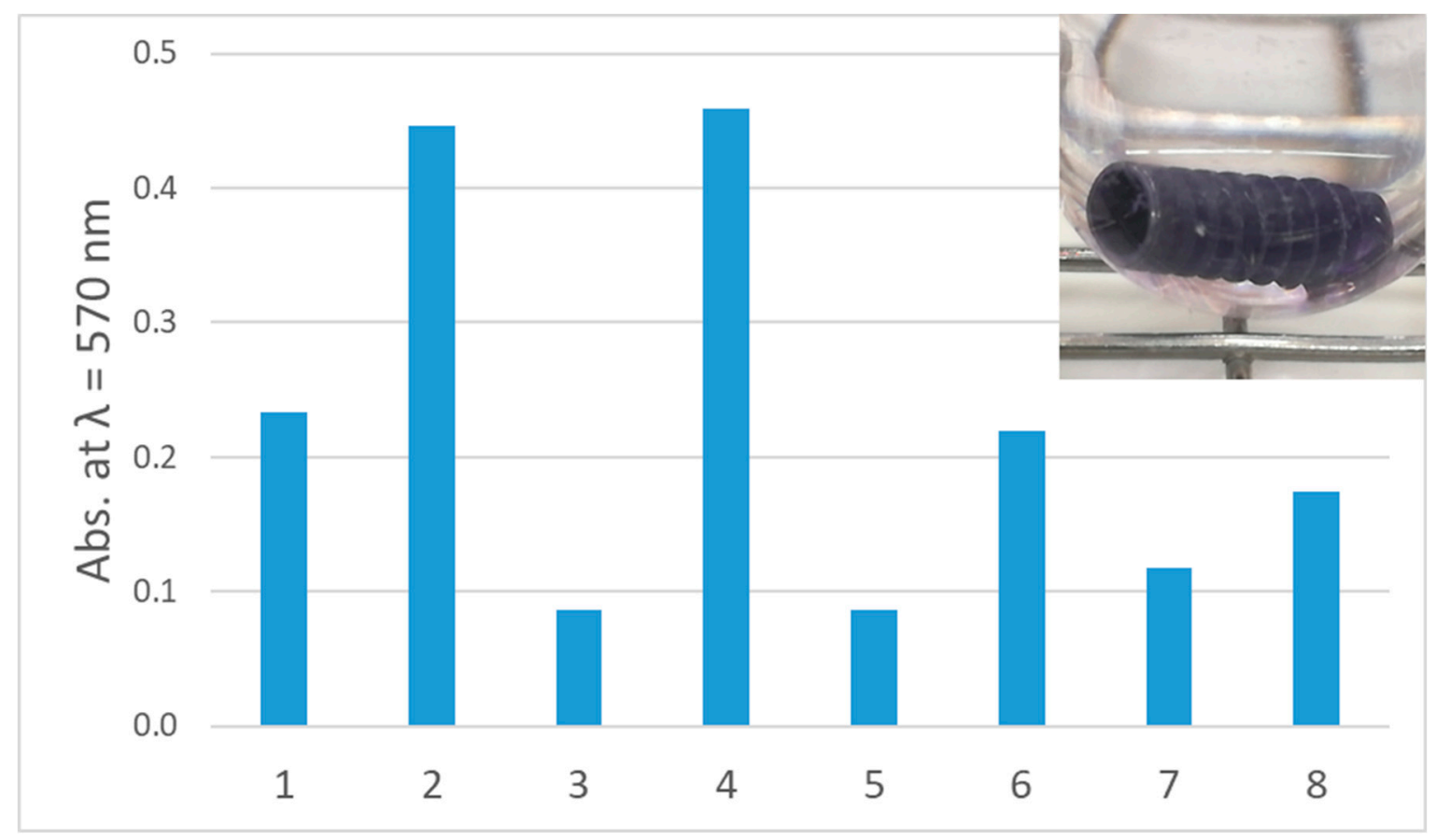

Figure 5. Biofilm formation on implants. Quantitative analysis of biofilm formation: (1) B. pumilus, (2) B. subtilis, (3) C. albicans, (4) C. dubliniensis, (5) E. faecalis, (6) R. mucosa, (7) S. epidermidis, (8) S. sanguinis. Inset: Crystal violet staining of R. mucosa biofilm.

\subsection{Removal of Biofilm from Implants Contaminated with C. dubliniensis}

BDD application to implants placed in both, silicone and polyurethane foam for $10 \mathrm{~min}$ at constant $6 \mathrm{~V}$ was at least as effective as the control treatments i.e. mechanical debridement and air abrasion. Increasing the treatment times of BDD electrodes led to even better results (Figure 6).

\subsection{Removal of Biofilm from Implants Contaminated with E. faecalis}

Mechanical debridement and air abrasion were not suitable for complete elimination of E. faecalis biofilm and disinfection of the implants (Figure 7). In contrast, using BDD electrode treatment, full removal of biofilm and complete disinfection of implants was achieved within 5 to $10 \mathrm{~min}$ depending on the model system used (Figure 7). 

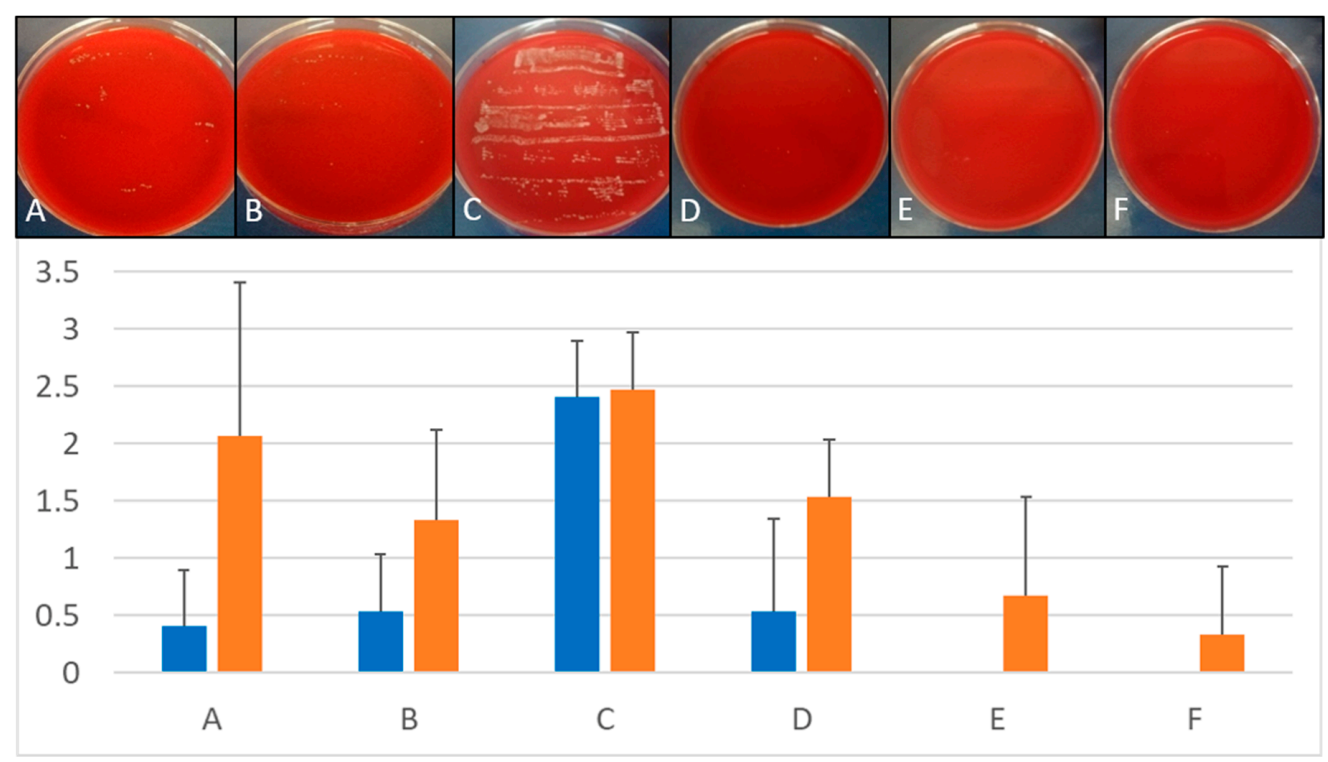

Figure 6. Treatment of $C$. dubliniensis biofilms. Upper panel: Comparison of growth on Columbia Blood Agar plates after different treatment of implants infected with C. dubliniensis and placed in silicone. Lower panel: Quantitative comparison of growth on implants inserted in silicone (blue bars) and polyurethane foam (orange) depending on treatment protocols. (A) Mechanical debridement, (B) air abrasion, (C) BDD treatment for $0 \mathrm{~min}$, (D) BDD treatment for $5 \mathrm{~min}$, (E) BDD treatment for $10 \mathrm{~min}$, (F) BDD treatment for $15 \mathrm{~min}$ ( $n=3$ for each methods and time point). Growth of implant roll-outs was rated from 0 (no growth) to 3 (strong growth). Columns represent the mean of 3 independent biological replicated \pm standard deviation $(\mathrm{SD})$.
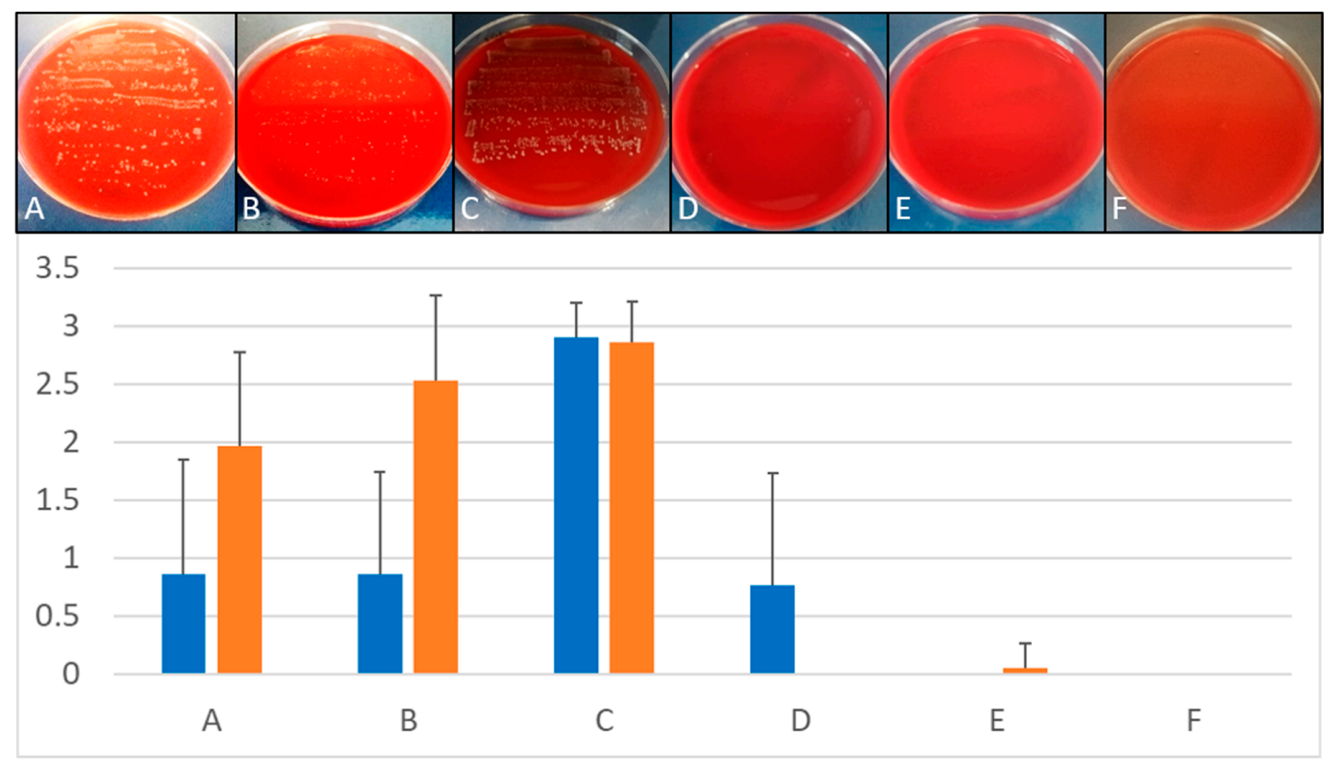

Figure 7. Treatment of E. faecalis biofilms. Upper panel: Comparison of growth on Columbia Blood Agar plates after different treatment of implants infected with E. faecalis and placed in silicone. Lower panel: Quantitative comparison of growth on implants inserted in silicone (blue bars) and polyurethane foam (orange bars) depending on treatment protocols. (A) Mechanical debridement, (B) air abrasion, (C) BDD treatment for $0 \mathrm{~min},(\mathbf{D})$ BDD treatment for $5 \mathrm{~min}$, (E) BDD treatment for $10 \mathrm{~min}$, (F) BDD treatment for $15 \mathrm{~min}$ ( $n=3$ for each methods and time point). Growth of implant roll-outs was rated from 0 (no growth) to 3 (strong growth). Columns represent the mean of 3 independent biological replicated \pm standard deviation $(\mathrm{SD})$. 


\subsection{Removal of Multispecies Biofilms from Implants}

When bovine ribs were used to insert implants, a multi-species colonization was observed, despite the fact that only E. faecalis was used for pre-incubation and colonization. Obviously, the tested bone material was already strongly contaminated with a number of different microorganisms and, consequently, a natural multi-species biofilm developed in the prepared bone. Treatment of these implants showed an inferior disinfection success. This result may be explained by the putative presence of spore-forming bacteria in the uncharacterized natural multi-species biofilm and the fact that bone debris, which was not removed prior to rolling the specimens on the blood agar plates, was sticking on the implant surface. However, compared to mechanical debridement and air abrasion, BDD treatment still performed best (Figure 8).
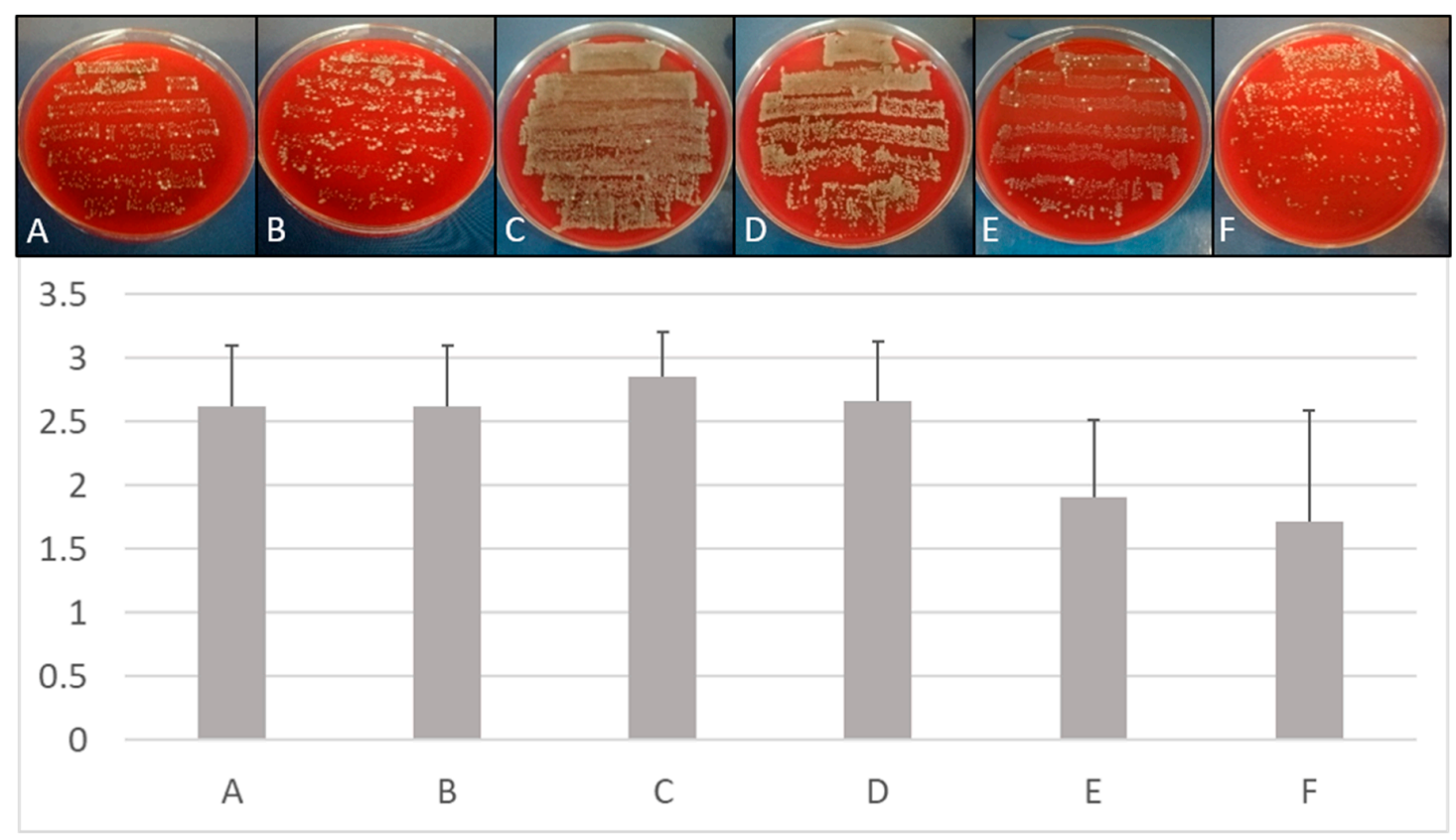

Figure 8. Treatment of multi-species biofilms. Upper panel: Comparison of growth on Columbia Blood Agar plates after different treatment of implants placed in bovine cadaver bone. Lower panel: Quantitative comparison of growth on implants inserted in ribs depending on treatment protocols. (A) Mechanical debridement, (B) air abrasion, (C) BDD treatment for $0 \mathrm{~min}$, (D) BDD treatment for $5 \mathrm{~min}$, (E) BDD treatment for $10 \mathrm{~min}$, (F) BDD treatment for $15 \mathrm{~min}$ ( $n=3$ for each methods and time point). Growth of implant roll-outs was rated from 0 (no growth) to 3 (strong growth). Columns represent the mean of 3 independent biological replicated \pm standard deviation (SD).

\subsection{Statistical Comparison Between Treatment Methods}

The mean values of the ratings as well as the results of the Kruskal Wallis rank sum tests for comparing the three different treatment modalities are given in Table 2. In no instance, a statistically significant difference could be observed between the disinfection techniques applied. 
Table 2. Mean values and standard deviations of ratings recorded for implants contaminated with E. faecalis, C. dubliniensis (implants placed in silicone or polyurethane foam) and multispecies biofilm (implants placed in bovine rib) following 5 min of treatment with mechanical debridement, air abrasion and BDD electrode ( $n=3$ per microorganism and treatment method). Comparative statistics did not reveal any significant differences among the three modalities $(p>0.05)$.

\begin{tabular}{|c|c|c|c|c|c|c|c|c|c|}
\hline \multirow{2}{*}{ Microbial Species } & \multicolumn{2}{|c|}{$\begin{array}{l}\text { Mechanical } \\
\text { Debridement }\end{array}$} & \multicolumn{2}{|c|}{ Air Abrasion } & \multicolumn{2}{|c|}{$\begin{array}{l}\text { Electrochemical } \\
\text { Disinfection }\end{array}$} & \multirow{2}{*}{$\begin{array}{l}\text { Kruskal Wallis } \\
\text { Chi-squared }\end{array}$} & \multirow{2}{*}{ df } & \multirow{2}{*}{$p$-Value } \\
\hline & Mean & SD & Mean & SD & Mean & SD & & & \\
\hline E. faecalis, polyurethane & 1.90 & 0.83 & 2.50 & 0.76 & 0.00 & 0.00 & 5.804 & 2 & 0.055 \\
\hline E. faecalis, silicone & 0.86 & 1.01 & 0.86 & 0.91 & 0.76 & 1.00 & 0.067 & 2 & 0.967 \\
\hline $\begin{array}{l}\text { C. dubliniensis, } \\
\text { polyurethane }\end{array}$ & 2.07 & 1.39 & 1.33 & 0.82 & 1.53 & 0.52 & 0.605 & 2 & 0.739 \\
\hline C. dubliniensis, silicone & 0.40 & 0.51 & 0.53 & 0.52 & 0.53 & 0.83 & 0.487 & 2 & 0.784 \\
\hline $\begin{array}{l}\text { Multi-species biofilm, } \\
\text { bovine rib }\end{array}$ & 2.62 & 0.50 & 2.62 & 0.50 & 2.67 & 0.48 & 0.318 & 2 & 0.853 \\
\hline
\end{tabular}

\subsection{Time-Dependent Removal of Biofilm from Implants Contaminated with Different Microorganisms}

In addition to the microorganisms mentioned above and multi-species biofilm, the effect of BDD electrode treatment on mono-species biofilms formed by a number of different bacteria and yeasts was tested. The fastest elimination (within $10 \mathrm{~min}$ ) was achieved for E. faecalis, R. mucosa, S. sanguinis and C. dubliniensis. A slightly longer treatment time of $20 \mathrm{~min}$ was necessary for the disinfection of implants colonized by C. albicans and S. epidermidis. In case of spore-forming B. pumilus and B. subtilis, a significant reduction of growth but no complete disinfection was reached under the experimental conditions applied due to the formation of highly resistant spores (6 V, 5-22 mA) (Table 3).

Table 3. Time for disinfection of implants placed in silicone depending on biofilm-forming species. All experiments were carried out in three independent biological replicates $(n=3)$ and the longest necessary treatment time is given. Implants were pre-incubated with the respective microorganisms to allow biofilm formation for three to five days.

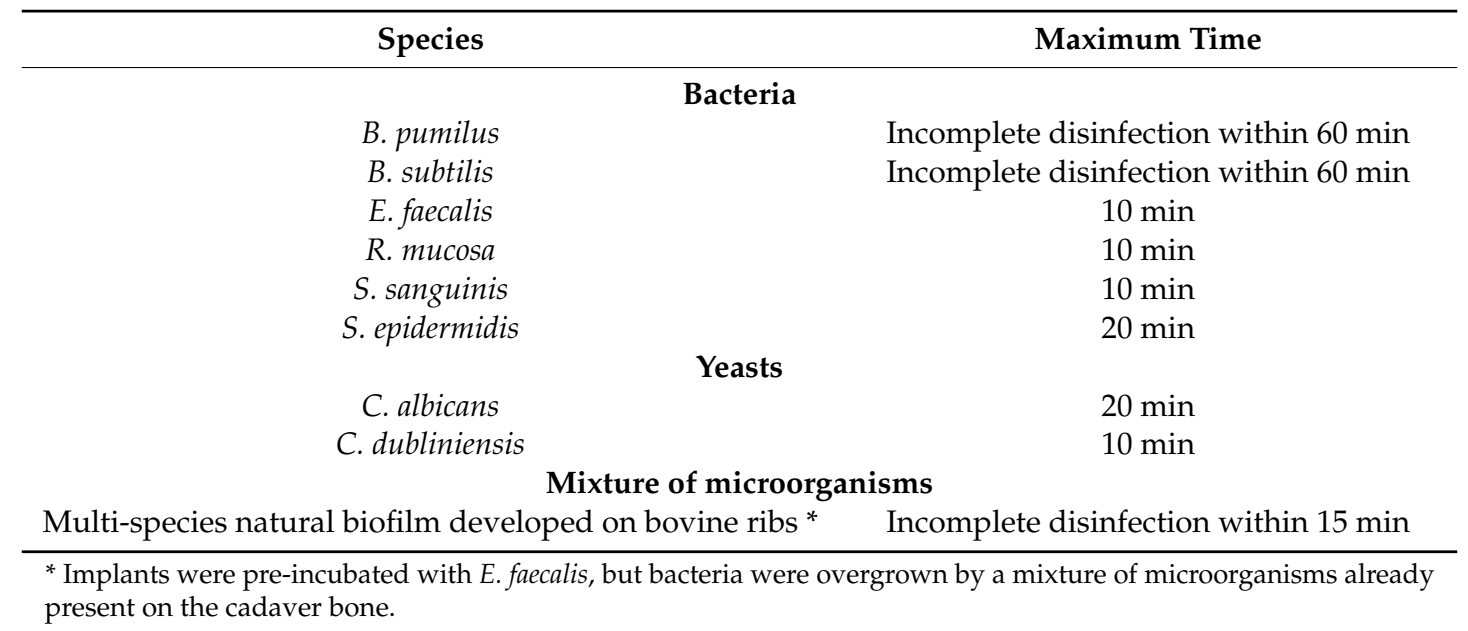

\subsection{Influence of $B D D$ Electrode Treatment on Temperature and $p H$}

Successful treatment of periimplantitis must not only rely on a reproducible disinfection protocol, but also on the absence of negative side effects. Therefore, changes in physico-chemical parameters depending on BDD treatment were tested. After treatment times of $25 \mathrm{~min}$, changes in temperature in the range of $2{ }^{\circ} \mathrm{C}$ and changes in $\mathrm{pH}$ of 1 unit were recorded in a controlled setting with a reaction tube filled with $4 \mathrm{ml}$ of phosphate-buffered saline and the respective probes mounted in the direct surrounding of the electrodes (Figure 9). 


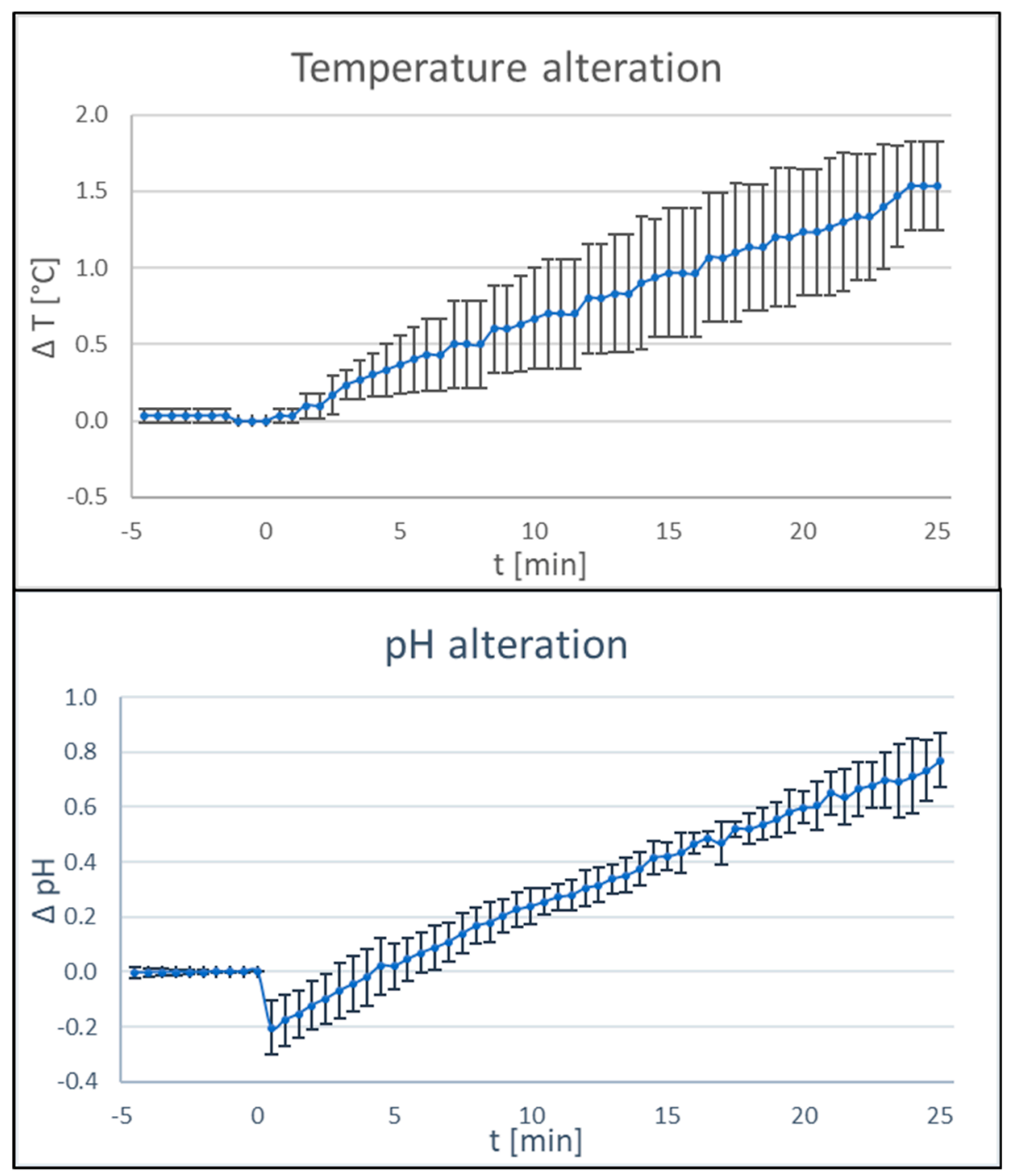

Figure 9. Influence of BDD electrode treatment on physico-chemical parameters. Changes in $\mathrm{pH}$ (upper panel) and temperature (lower panel) during application of the BDD electrode in phosphate-buffered saline was tested. For each parameter, three independent experiments were carried out $n=3$, current 15-20 mA; voltage $6 \mathrm{~V}$ ).

\section{Discussion}

Despite using a simplistic prototype, it was shown that electrochemical disinfection of contaminated implant surfaces was possible when BDD electrodes based on niobium wires were used. In contrast to mechanical debridement damaging the implant surface and air powder abrasion leaving powder remnants on the implant surface, no alterations of the implant surfaces were identified with the use of BDD electrodes [54]. As expected, the different microbes tested in this study showed varying levels of sensitivity and hence required varying amounts of treatment time until complete disinfection was achieved. The worst performer in this respect were, besides an uncharacterized multi-species biofilm, B. pumilus and B. subtilis, both forming highly resistant spores under the experimental conditions applied, while E. faecalis, R. mucosa and S. sanguinis were safely eliminated with a maximum treatment time of $10 \mathrm{~min}$. With the non-optimized setup used here, these treatment times would be too long for clinical application. The critical aspect, however, is not the treatment time but the charge quantity applied. Future developments will hence include modified electrodes with increased surfaces.

Minor temperature and $\mathrm{pH}$-value changes were observed after applying the electrodes for approximately $25 \mathrm{~min}$ and hence would not be expected in a clinical setting where clearly shorter 
treatment times are needed. Even if these changes would occur, negative effects on the patient cannot be expected.

It had been anticipated that disinfection would become more difficult when implants are placed in bone surrogate materials or cadaver bone as compared to having full access to all critical surfaces. While not expressible as a quantitative effect, this correlation was observed for the control treatments of chemo-mechanical debridement and air abrasion, respectively. In contrast, when electrochemical disinfection was applied, restricted access to implant surfaces obviously had less effect.

Recently, an electro-chemical approach for implant debridement and periimplantitis treatment was introduced utilizing the implant itself as an electrode (cathode) while a wire, not contacting the infected surface, was used as another electrode (anode) [44]. By this approach, not using BDD-coated electrodes, biofilm appears to be primarily removed by bubbles of electrochemically generated hydrogen at the cathodic implant surface. This theoretically bears the risk of spreading the biofilm into the surrounding tissue and may also generate corrosion problems on the implant surface by hindering the self-passivation of titanium after damaging the native oxide layer by a mechanical load. Furthermore, the hydrogen uptake of the titanium implant can lower the mechanical strength of the material by hydrogen embrittlement [55].

Given that the experiment at hand constituted the first application of BDD electrodes for biofilm removal from dental implant surfaces, a number of limitations have to be taken into account when interpreting the findings presented. A wide variety of bacteria and yeasts have been shown to be present in dental biofilms, while in the current experiment mostly mono-species biofilms were considered. Although different bacteria may form a synergistic biofilm, their resistance to disinfecting measures is not influenced by other species. However, with the spore-forming species used here, a worst-case scenario has already been tested. It has been shown that not only the clinical situation per se but also the defect morphology impacts the result of periimplantitis treatment [52]. As such, the model situations chosen here clearly present simplifications of reality, which were needed due to the prototypical stage of the BDD electrode setup. Due to the exploratory nature of this pilot investigation, comparative statistical analysis among the treatment modalities applied was limited to a subset of experiments where implants had been treated for exactly 5 min using all three disinfection methods. Future studies are under way with much greater sample size aimed at quantitatively comparing different treatment modalities.

Taking into account that numerous developmental steps including preclinical and clinical studies will be required prior to clinical application of an instrument based on a BDD electrode array, a probe-like instrument with a permeable cover can already be envisaged. Not requiring superstructure removal as well as the universal applicability also in periodontal and endodontic treatment would be major advantages of such an instrument.

\section{Patents}

Stefan Rosiwal, Andreas Burkovski, Maximilian Göltz and Matthias Karl have a filed a patent for the disinfection method described in this report.

Supplementary Materials: The following are available online at http://www.mdpi.com/2077-0383/9/2/475/s1, Table S1: Overview of disinfection experiments. Sample size and groups are given for organisms and treatment methods applied (n.d., not determined). Embedment methods used: silicone, polyurethane foam and bovine ribs.

Author Contributions: A.B., M.K. (Matthias Karl) and S.R. were involved in conceptualization of the study, M.G. carried out diamond coating of niobium wires, M.K. (Maximilian Koch) designed the protoype electrode, M.K. (Maximilian Koch) and M.X. carried out corresponding experiments. A.B. supervised the microbiology work, S.R. the diamond-coating process. Writing and original draft preparation was carried out by A.B., M.K. (Matthias Karl) and S.R., A.B. and M.K. (Matthias Karl) finalized the manuscript. M.K. (Matthias Karl) was involved in funding acquisition. All authors have read and agreed to the published version of the manuscript.

Funding: This project was supported by a grant (1328_2018) from the ITI Foundation, Switzerland.

Acknowledgments: We acknowledge support by the Deutsche Forschungsgemeinschaft (DFG, German Research Foundation) and Saarland University within the funding programme Open Access Publishing. The authors 
wish to thank Friedrich Graef, Department of Mathematics, University of Erlangen-Nuremberg for statistical data analysis.

Conflicts of Interest: The authors declare no conflict of interest.

\section{References}

1. Pimentel, S.P.; Shiota, R.; Cirano, F.R.; Casarin, R.C.V.; Pecorari, V.G.A.; Casati, M.Z.; Haas, A.N.; Ribeiro, F.V. Occurrence of peri-implant diseases and risk indicators at the patient and implant levels: A multi-level cross-sectional study. J. Periodontol. 2018, 89, 1091-1100. [CrossRef] [PubMed]

2. Dreyer, H.; Grischke, J.; Tiede, C.; Eberhard, J.; Schweitzer, A.; Toikkanen, S.E.; Glöckner, S.; Krause, G.; Stiesch, M. Epidemiology and risk factors of peri-implantitis: A systematic review. J. Periodontal. Res. 2018, 53, 657-681. [CrossRef] [PubMed]

3. Lin, G.H.; Kapila, Y.; Wang, H.L. Parameters to define peri-implantitis: A review and a proposed multi-domain scale. J. Oral Implantol. 2017, 43, 491-496. [CrossRef] [PubMed]

4. Rakic, M.; Galindo-Moreno, P.; Monje, A.; Radovanovic, S.; Wang, H.L.; Cochran, D.; Sculean, A.; Canullo, L. How frequent does peri-implantitis occur? A systematic review and meta-analysis. Clin. Oral Invest. 2018, 22, 1805-1816. [CrossRef]

5. Derks, J.; Schaller, D.; Håkansson, J.; Wennström, J.L.; Tomasi, C.; Berglundh, T. Effectiveness of implant therapy analyzed in a Swedish population: Prevalence of peri-implantitis. J. Dental Res. 2016, 95, 43-49. [CrossRef]

6. Kane, G.; Fang, V.; Simon, S.; Girdler, J.; Adeyinka, O.; Alhilou, A. A survey exploring the experiences \& attitudes of dental implant clinicians in the management of peri-implantitis within the United Kingdom. Eur. J. Prosthodont. Restor. Dent. 2018, 26, 46-52. [CrossRef]

7. Albrektsson, T.; Buser, D.; Sennerby, L. Crestal bone loss and oral implants. Clin. Implant Dent. Relat. Res. 2012, 14, 783-791. [CrossRef]

8. Albrektsson, T.; Canullo, L.; Cochran, D.; De Bruyn, H. "Peri-implantitis": A complication of a foreign body or a man-made "disease". Facts and fiction. Clin. Impl. Dent. Relat. Res. 2016, 18, 840-849. [CrossRef]

9. Kumar, P.S.; Dabdoub, S.M.; Hegde, R.; Ranganathan, N.; Mariotti, A. Site-level risk predictors of peri-implantitis: A retrospective analysis. J. Clin. Periodontol. 2018, 45, 597-604. [CrossRef]

10. Derks, J.; Håkansson, J.; Wennström, J.L.; Tomasi, C.; Larsson, M.; Berglundh, T. Effectiveness of implant therapy analyzed in a Swedish population: Early and late implant loss. J. Dent. Res. 2015, 94, 44S-51S. [CrossRef]

11. Korsch, M.; Robra, B.P.; Walther, W. Cement-associated signs of inflammation: Retrospective analysis of the effect of excess cement on peri-implant tissue. Int. J. Prosthodont. 2015, 28, 11-18. [CrossRef] [PubMed]

12. Pesce, P.; Canullo, L.; Grusovin, M.G.; de Bruyn, H.; Cosyn, J.; Pera, P. Systematic review of some prosthetic risk factors for periimplantitis. J. Prosthet. Dent. 2015, 114, 346-350. [CrossRef] [PubMed]

13. Al-Ahmad, A.; Muzafferiy, F.; Anderson, A.C.; Wölber, J.P.; Ratka-Krüger, P.; Fretwurst, T.; Nelson, K.; Vach, K.; Hellwig, E. Shift of microbial composition of peri-implantitis-associated oral biofilm as revealed by 16S rRNA gene cloning. J. Med. Microbiol. 2018, 67, 332-340. [CrossRef] [PubMed]

14. Gallego, L.; Sicilia, A.; Sicilia, P.; Mallo, C.; Cuesta, S.; Sanz, M. A retrospective study on the crestal bone loss associated with different implant surfaces in chronic periodontitis patients under maintenance. Clin. Oral Implants Res. 2018, 29, 557-567. [CrossRef] [PubMed]

15. Eggert, F.M.; Levin, L. Biology of teeth and implants: Host factors - pathology, regeneration, and the role of stem cells. Quintessence Int. 2018, 49, 497-509. [CrossRef] [PubMed]

16. Bastos, M.F.; de Franco, L.; Garcia Tebar, A.C.; Giro, G.; Shibli, J.A. Expression levels of Semaphorins 3A, 3B, 4A, and 4D on human peri-implantitis. Int. J. Oral Maxillofac. Implants 2018, 33, 565-570. [CrossRef]

17. Patianna, G.; Valente, N.A.; D'Addona, A.; Andreana, S. In vitro evaluation of controlled-release $14 \%$ doxycycline gel for decontamination of machined and sandblasted acid-etched implants. J. Periodontol. 2018, 89, 325-330. [CrossRef]

18. Bombeccari, G.P.; Guzzi, G.; Gualini, F.; Gualini, S.; Santoro, F.; Spadari, F. Photodynamic therapy to treat periimplantitis. Implant Dent. 2013, 22, 631-638. [CrossRef]

19. Kasnak, G.; Firatli, E.; Könönen, E.; Olgac, V.; Zeidán-Chuliá, F.; Gursoy, U.K. Elevated levels of 8-OHdG and PARK7/DJ-1 in peri-implantitis mucosa. Clin. Implant Dent. Relat. Res. 2018, 20, 574-582. [CrossRef] 
20. Wong, R.L.; Hiyari, S.; Yaghsezian, A.; Davar, M.; Casarin, M.; Lin, Y.L.; Tetradis, S.; Camargo, P.M.; Pirih, F.Q. Early intervention of peri-implantitis and periodontitis utilizing a mouse model. J. Periodontol. 2018, 89, 669-679. [CrossRef]

21. Berglundh, T.; Armitage, G.; Araujo, M.G.; Avila-Ortiz, G.; Blanco, J.; Camargo, P.M.; Chen, S.; Cochran, D.; Derks, J.; Figuero, E. Peri-implant diseases and conditions: Consensus report of workgroup 4 of the 2017 World Workshop on the Classification of Periodontal and Peri-Implant Diseases and Conditions. J. Clin. Periodontol 2018, 45 (Suppl. 20), S286-S291. [CrossRef]

22. Albrektsson, T.; Chrcanovic, B.; Östman, P.O.; Sennerby, L. Initial and long-term crestal bone responses to modern dental implants. Periodontol. 2000 2017, 73, 41-50. [CrossRef] [PubMed]

23. Mercado, F.; Hamlet, S.; Ivanovski, S. Regenerative surgical therapy for peri-implantitis using deproteinized bovine bone mineral with 10\% collagen, enamel matrix derivative and Doxycycline-A prospective 3-year cohort study. Clin. Oral Implants. Res. 2018, 29, 583-591. [CrossRef] [PubMed]

24. Monje, A.; Caballé-Serrano, J.; Nart, J.; Peñarrocha, D.; Wang, H.L.; Rakic, M. Diagnostic accuracy of clinical parameters to monitor peri-implant conditions: A matched case-control study. J. Periodontol. 2018, 89, 407-417. [CrossRef] [PubMed]

25. Ramanauskaite, A.; Becker, K.; Schwarz, F. Clinical characteristics of peri-implant mucositis and peri-implantitis. Clin. Oral Implants Res. 2018, 29, 551-556. [CrossRef] [PubMed]

26. Sinjab, K.; Garaicoa-Pazmino, C.; Wang, H.L. Decision making for management of periimplant diseases. Implant Dent. 2018, 27, 276-281. [CrossRef]

27. Isehed, C.; Svenson, B.; Lundberg, P.; Holmlund, A. Surgical treatment of peri-implantitis using enamel matrix derivative, an RCT: 3- and 5-year follow-up. J. Clin. Periodontol. 2018, 45, 744-753. [CrossRef]

28. Berglundh, T.; Wennström, J.L.; Lindhe, J. Long-term outcome of surgical treatment of peri-implantitis. A 2-11-year retrospective study. Clin. Oral Implants Res. 2018, 29, 404-410. [CrossRef]

29. Gershenfeld, L.; Kalos, A.; Whittle, T.; Yeung, S. Randomised clinical trial of the effects of azithromycin use in the treatment of peri-implantitis. Aust. Dent. J. 2018. [CrossRef]

30. Ribeiro, F.V.; Casati, M.Z.; Casarin, R.C.; Corrêa, M.G.; Cirano, F.R.; Negri, B.M.; Pimentel, S.P. Impact of a triclosan-containing toothpaste during the progression of experimental peri-implant mucositis: Clincal parameters and local pattern of osteo-immunoinflammatory mediators in peri-implant fluid. J. Periodontol. 2018, 89, 203-212. [CrossRef]

31. Carcuac, O.; Derks, J.; Abrahamsson, I.; Wennström, J.L.; Petzold, M.; Berglundh, T. Surgical treatment of peri-implantitis: 3-year results from a randomized controlled clinical trial. J. Clin. Periodontol. 2017, 44, 1294-1303. [CrossRef] [PubMed]

32. Takagi, T.; Aoki, A.; Ichinose, S.; Taniguchi, Y.; Tachikawa, N.; Shinoki, T.; Meinzer, W.; Sculean, A.; Izumi, Y. Effective removal of calcified deposits on microstructured titanium fixture surfaces of dental implants with erbium lasers. J. Periodontol. 2018, 89, 680-690. [CrossRef] [PubMed]

33. Ramos, U.D.; Suaid, F.; Wikesjö, U.M.; Susin, C.; Vital, P.C.; de Souza, S.L.S.; Messora, M.R.; Palioto, D.B.; Novaes, A.B., Jr. Microbiologic effect of two topical anti-infective treatments on ligature-induced peri-implantitis: A pilot study in dogs. J. Periodontol. 2018, 89, 995-1002. [CrossRef] [PubMed]

34. Fraga, R.S.; Antunes, L.A.A.; Fontes, K.B.F.D.C.; Küchler, E.C.; Iorio, N.L.P.P.; Antunes, L.S. Is antimicrobial photodynamic therapy effective for microbial load reduction in peri-implantitis treatment? A systematic review and meta-analysis. Photochem. Photobiol. 2018, 94, 752-759. [CrossRef]

35. Rupf, S.; Idlibi, A.N.; Marrawi, F.A.; Hannig, M.; Schubert, A.; von Mueller, L.; Spitzer, W.; Holtmann, H.; Lehmann, A.; Rueppell, A.; et al. Removing biofilms from microstructured titanium ex vivo: A novel approach using atmospheric plasma technology. PLoS. ONE 2011, 6, e25893. [CrossRef]

36. Idlibi, A.N.; Al-Marrawi, F.; Hannig, M.; Lehmann, A.; Rueppell, A.; Schindler, A.; Jentsch, H.; Rupf, S. Destruction of oral biofilms formed in situ on machined titanium (Ti) surfaces by cold atmospheric plasma. Biofouling 2013, 29, 369-379. [CrossRef]

37. Lee, S.T.; Subu, M.G.; Kwon, T.G. Emphysema following air-powder abrasive treatment for peri-implantitis. Maxillofac. Plast Reconstr. Surg. 2018, 40, 12. [CrossRef]

38. Tastepe, C.S.; Lin, X.; Werner, A.; Donnet, M.; Wismeijer, D.; Liu, Y. Cleaning effect of osteoconductive powder abrasive treatment on explanted human implants and biofilm-coated titanium discs. Clin. Exp. Dent. Res. 2018, 4, 25-34. [CrossRef] 
39. Wei, M.C.T.; Tran, C.; Meredith, N.; Walsh, L.J. Effectiveness of implant surface debridement using particle beams at differing air pressures. Clin. Exp. Dent. Res. 2017, 3, 148-153. [CrossRef]

40. Rosen, P.S.; Qari, M.; Froum, S.J.; Dibart, S.; Chou, L.L. A pilot study on the efficacy of a treatment algorithm to detoxify dental implant surfaces affected by peri-implantitis. Int. J. Periodontics Restorative Dent. 2018, 38, 261-267. [CrossRef]

41. Stein, J.M.; Hammächer, C.; Michael, S.S. Combination of ultrasonic decontamination, soft tissue curettage, and submucosal air polishing with povidone-iodine application for non-surgical therapy of peri-implantitis: 12 Month clinical outcomes. J. Periodontol. 2017. [CrossRef] [PubMed]

42. Madi, M.; Htet, M.; Zakaria, O.; Alagl, A.; Kasugai, S. Re-osseointegration of dental implants after periimplantitis treatments: A systematic review. Implant Dent. 2018, 27, 101-110. [CrossRef] [PubMed]

43. Larsen, O.I.; Enersen, M.; Kristoffersen, A.K.; Wennerberg, A.; Bunæs, D.F.; Lie, S.A.; Leknes, K.N. Antimicrobial effects of three different treatment modalities on dental implant surfaces. J. Oral Implantol. 2017, 43, 429-436. [CrossRef]

44. Schneider, S.; Rudolph, M.; Bause, V.; Terfort, A. Electrochemical removal of biofilms from titanium dental implant surfaces. Bioelectrochemistry 2018, 121, 84-94. [CrossRef] [PubMed]

45. Kraft, A. Doped diamond: A compact review on a new, versatile electrode material. Int. J. Electrochem. Sci. 2007, 2, 355-385.

46. Schorr, B.; Ghanem, H.; Rosiwal, S.; Geißdörfer, W.; Burkovski, A. Elimination of bacterial contaminations by treatment of water with boron-doped diamond electrodes. World J. Microbiol. Biotechnol. 2019, 35, 48. [CrossRef]

47. Böhm, A.-L.; Koch, M.; Rosiwal, S.; Burkovski, A.; Karl, M. Grobecker-Karl, T. Electrochemical disinfection of experimentally infected teeth by boron-doped diamond electrode treatment. J. Clin. Med. 2019, 8, 2037. [CrossRef]

48. O'Toole, G.A.; Kolter, R. Initiation of biofilm formation in Pseudomonas fluorescens WCS365 proceeds via multiple, convergent signaling pathways: A genetic analysis. Mol. Microbiol. 1998, 28, 449-461. [CrossRef]

49. Burkovski, A.; Karl, M. Lack of evidence for the necessity of root canal obturation. Quintessence Int. 2019, 50, 2-8.

50. Diesendorf, N.; Köhler, S.; Geißdörfer, W.; Grobecker-Karl, T.; Karl, M.; Burkovski, A. Characterisation of Roseomonas mucosa isolated from the root canal of an infected tooth. BMC. Res. Notes 2017, 10, 212. [CrossRef]

51. Lekholm, U.; Zarb, G.A. Patient selection and preparation. In Tissue Integrated Prostheses: Osseointegration in Clinical Dentistry; Branemark, P.-I., Zarb, G.A., Albrektsson, T., Eds.; Quintessence Publishing: Chicago, IL, USA, 1985; pp. 199-209.

52. Schwarz, F.; Sahm, N.; Schwarz, K.; Becker, J. Impact of defect configuration on the clinical outcome following surgical regenerative therapy of peri-implantitis. J. Clin. Periodontol. 2010, 37, 449-455. [CrossRef] [PubMed]

53. Maki, D.G.; Weise, C.E.; Sarafin, H.W. A semiquantitative culture method for identifying intravenous-catheter-related infection. N. Engl. J. Med. 1977, 296, 1305-1309. [CrossRef] [PubMed]

54. Göltz, M.; Koch, M.; Detsch, R.; Karl, M.; Burkovski, A.; Rosiwal, S. Influence of in-situ electrochemical oxidation on implant surface and colonizing microorganisms evaluated by scatter electron microscopy. Materials 2019, 12, 3977. [CrossRef]

55. Tal-Gutelmacher, E.; Eliezer, D. The hydrogen embrittlement of titanium-based alloys. J. Min. Met. Mat. Soc. 2005, 9, 46-49. [CrossRef]

(C) 2020 by the authors. Licensee MDPI, Basel, Switzerland. This article is an open access article distributed under the terms and conditions of the Creative Commons Attribution (CC BY) license (http://creativecommons.org/licenses/by/4.0/). 